\title{
SISTEM INFORMASI PELAYANAN JASA TOUR DAN TRAVEL BERBASIS WEB (STUDI KASUS SMART TOUR)
}

\author{
Sampurna Dadi Riskiono \\ FAKULTAS TEKNIK DAN ILMU KOMPUTER \\ UNIVERSITAS TEKNOKRAT INDONESIA \\ Email: sampurna.go@teknokrat.ac.id \\ Urip Reginal \\ Prodi S1 Informatika \\ FAKULTAS TEKNIK DAN ILMU KOMPUTER \\ UNIVERSITAS TEKNOKRAT INDONESIA \\ ureginal95@gmail.com
}

\begin{abstract}
Abstrak
Smart Tour adalah salah satu biro perjalan Tour yang ada di Bandarlampung. Smart Tour ini sudah berpengalaman di banyak industri bisnis pariwisata bukan hanya biro perjalanan, tetapi Smart Tour ini juga mempunyai jasa property dan Rental Mobil. Selama ini sistem yang ada masih belum sesuai dengan kebutuhan masyarakat, dikarenakan proses pemesanan tiket masih dilakukan secara manual. Masyarakat harus datang langsung ke Smart Tour untuk memesan tiket liburan lokal maupun domestic. Smart Tour juga menyediakan jasa Penyewaan Mobil dimana sistem yang ada sebelumnya masih dicatat secara manual dan belum terkomputerisasi. Metode Extreme Programing adalah salah satu metode pengembangan perangkat lunak yang termasuk agile development yang menggunakan pendekatan object oriented dan mencakup seperangkat aturan yang terjadi dalam kegiatan. Planning,design,coding, dan testing. Metode Extreme Programing ini dipilih karena dalam proses pembuatan suatu perangkat lunak sangat cepat dan sesuai dengan project yang siap di bangun. Dalam pembuatan suatu project perangkat lunak pasti ada kesalahan, tetapi di metode ini setiap ada kesalahan akan langsung di perbaiki tanpa harus mengulang semua kesalahan yag telah ada sebelumnya. Sistem yang telah kembangkan di Smart tour ini adalah Website karena dapat di akses dimana saja dan dapat mempermudah dalam proses transaksi, pengelolaan data dan pemesanan paket pariwisata. Berdasarkan penelitian yang telah di bangun tentang Sistem informasi pelayanan jasa tour dan travel berbasis web (Studi kasus Smart Tour) dapat mampu mengurangi resiko kesalahan pada pengelolaan data pada admin dan Sistem informasi pelayanan jasa tour dan travel berbasis web (Studi kasus Smart Tour) telah mampu mengurangi waktu yang terbuang pada saat pelanggan memesan tiket tour dengan menghasilkan kriteria baik yaitu persentase tanggapan responden sebesar $100 \%$.
\end{abstract}

Kata kunci: Sistem Informasi Smart Tour dan Travel, berbasis Website dengan metode Extreme Programing 


\begin{abstract}
Abstrack
Smart Tour is one of the tour travel bureaus in Bandarlampung. This Smart Tour is already experienced in many tourism business industries not just travel agencies, but this Smart Tour also has property and Car Rental services. So far the existing system is still not in accordance with the needs of the community, because the ticket reservation process is still done manually. The public must come directly to the Smart Tour to book local and domestic vacation tickets. Smart Tour also provides Car Hire services where previously existing systems are still manually recorded and not yet computerized. The Extreme Programing method is one of the software development methods that includes agile development using object oriented approach and includes a set of rules that occur in the activity. Planning, design, coding, and testing. Extreme Programing method is chosen because in the process of making a software very quickly and in accordance with the project is ready to wake up. In making a software project there must be a mistake, but in this method any errors will be directly fixed without having to repeat all the errors that have been there before. The system that has been developed in this Smart tour is Website because it can be accessed anywhere and can ease in transaction processing, data management and booking of tourism package. Based on the research that has been built about information system webbased tour and travel services (case study Smart Tour) can be able to reduce the risk of errors in the management of data on the admin and information system web-based tour and travel services (case study Smart Tour) has been able reduce the time wasted when customers order tour tickets by generating good criteria that is the percentage of respondents $100 \%$.
\end{abstract}

Keywords: Smart Tour and Travel Information System, Website based with Extreme Programing method 


\section{PENDAHULUAN}

Smart Tour adalah salah satu biro perjalan Tour yang ada di Bandarlampung. Smart Tour ini sudah berpengalaman di banyak industri bisnis pariwisata bukan hanya biro perjalanan, tetapi Smart Tour ini juga mempunyai jasa property dan Rental Mobil. Selama ini sistem yang ada masih belum sesuai dengan kebutuhan masyarakat, dikarenakan proses pemesanan tiket masih dilakukan secara manual. Masyarakat harus datang langsung ke Smart Tour untuk memesan tiket liburan lokal maupun domestic. Smart Tour juga menyediakan jasa Penyewaan Mobil dimana sistem yang ada sebelumnya masih dicatat secara manual dan belum terkomputerisasi.

Disisi lain, adanya kehadiran teknologi informasi sangat membantu dalam menunjang kebutuhan manusia untuk mendapatkan

\subsection{Rumusan Masalah}

Berdasarkan latar belakang di atas, maka permasalahan yang dibahas antara lain :

1. Saat ini data paket Tour masih kurang lengkap sehingga pelayanan pada pelanggan masih kurang puas.

2. Saat ini sistem kelola paket Tour dan Travel yang dilakukan oleh admin masih manual karena pelanggan harus datang ke smart Tour untuk mengkonfirmasi paket kelola Tour maupun Travel yang dikelola oleh admin.

\subsection{Batasan Masalah}

Permasalahan penelitian ini dibatasi pada :

1. Memberikan informasi di smart Tour seperti Pemesanan Tiket pariwisata untuk lokal maupun domestik, Penyewaan rental mobil.

2. Dapat memberikan sistem pengolahan paket Tour dan Travel agar pelanggan tidak perlu datang untuk mengkonfirmasi informasi dalam waktu yang relatif cepat Diamana teknologi saat ini sangat mendukung untuk memenuhi kebutuhan informasi yang cepat, yaitu salah satunya adalah dengan dikembangkanya sistem informasi pelayanan jasa Tour dan Travel pada Smart Tour.

Dari permasalahan di atas maka dapat di sarikan terkait belum adanya sistem yang mampu mengatasi masalah dalam hal pemesanan tiket dan penyewaan mobil, sehingga masyarakat masih kesulitan untuk dapat melakukan pemesanan tiket dan penyewaan mobil secara online. Untuk itu diperlukan sistem informasi yang dapat menampilkan informasi pemesanan tiket dan penyewaan mobil secara online, sehingga informasi pemesanan tiket dan penyewaan mobil dapat dengan mudah diakses olehmasyarakat.

pemesanan paket Tour kepada admin smart Tour

\subsection{Manfaat Penelitian}

Manfaat dari penelitian ini adalah sebagai berikut :

1. Mempermudah pelayanan pemesanan tiket Tour dan Travel

2. Mempermudah dalam pengelola paket Tour dan Travel.

\subsection{Tujuan Penelitian}

Tujuan penelitian ini adalah membuat system yang berguna bagi masyarakat yang ingin liburan lokal maupun domestik, antara lain :

1. Menghasilkan Sistem pemberi informasi paket liburan pariwisata dan penyewaan Travel mobil.

2. Untuk mengurangi resiko kesalahan pada pengelolaan data pada admin

3. Untuk mengurangi waktu yang terbuang pada saat pelanggan memesan tiket Tour dikarenakan pemesanan sebelumnya harus melalui email dari pimpinan Smart tour.

53 | STMIK Dian Cipta Cendikia Kotabumi 


\section{a. Pengertian sistem}

Menurut Jogiyanto (2010), bahwa sistem dapat di definisikan dengan pendekatan prosedur dan dengan pendekatan komponen :

1. Dengan pendekatan prosedur, sistem dapat di definisikan sebagai kumpulan dari prosedur-prosedur yang mempunyai tujuan tertentu.

2. Dengan pendekatan komponen, sistem dapat didefinisikan sebagai kumpulan dari komponen yang saling berhubungan satu dengan yang lainya membentuk satu kesatuan untuk mencapai tujuan tertentu.

Dari pengertian diatas dapat di simpulkan bahwa sistem adalah suatu kumpulan dari suatu proses yang saling memiliki ketergantungan dan memiliki suatu tujuan tertentu.

\section{b. Karakteristik sistem}

Menurut Bahra (2013), karakteristik sistem merupakan suatu sistem yang mempunyai karakteristik atau sifat-sifat tertentu, yaitu mempunyai komponen-komponen, batas sistem, lingkungan luar sistem, penghubung, masukan, keluaran, pengolah dan sasaran atau tujuan.

Adapun penjelasan dari masing-masing karakteristik sistem menurut Bahra (2013) adalah sebagai berikut :

\section{Komponen sistem}

terdiri dari sejumlah komponenyang saling berinteraksi, yang artinya saling bekerjasama membentuk suatu kesatuan. Komponen-komponen bagian sistem.

\section{Batasan Sistem}

Batasan sistem merupakan daerah yang membatasi antara suatu sistem dengan sistem yang lainya atau dengan lingkungan luarnya. Batas sistem ini memungkinkan suatu sistem dipandang sebagai suatu kesatuan dan menunjukan ruang lingkup dari sistem tersebut.

\section{Lingkungan Luar Sistem}

Lingkungan luar dari suatu sistem adalah apapun diluar batas sistem yang mempengaruhi operasi sistem. Lingkungan luar sistem dapat bersifat menguntungkan dan juga merugikan.

\section{Penghubung Sistem}

Penghubung merupakan media yang menghubungkan antara satu subsistem dengan subsistem lainya, melalui penghubung ini kemungkinan sumbersumber daya mengalir dari satu subsistem ke subsistem lainya.

\section{Masukan Sistem}

Masukan sistem adalah tenaga yang dimasukkan ke dalam sistem, masukan dapat berupa perawatan dan masukkan sinyal maintenance input adalah energy yang dimasukkan supaya sistem tersebut dapat berjalan. Sinyal input adalah energy yang diproses untuk mendapatkan keluaran dari sistem.

\section{Keluaran Sistem}

Keluaran sistem adalah energy yang diolah dan di klasifikasikan menjadi keluaran yang berguna. Keluaran dapat merupakan masukan untuk subsistem yang lain.

\section{Pengolahan Sistem}

Suatu sistem dapat mempunyai suatu bagian pengolah atau sistem itu sendiri sebagai pengolahnya. Pengolah yang akan merubah masukkan menjadi keluaran.

\section{Sasaran Sistem}

Suatu sistem mempunyai tujuan atau aturan, kalau sistem tidak mempunyai sasaran maka sistem tidak akan ada. Suatu sistem dikatakan berhasil bila mengenai sasaran atau tujuannya. Sasaran sangat berpengaruh pada masukan

54 | STMIK Dian Cipta Cendikia Kotabumi 
dan keluaran yang dihasilkan.

\section{c. Sistem informasi}

Menurut Sutabri (2012), pengertian sistem informasi yaitu :

"Suatu sistem didalam suatu organisasi yang mempertemukan kebutuhan bersifat manajerial dengan kegiatan strategi dari suatu organisasi untuk dapat menyediakan kepada pihak luar tertentu dengan laporan-laporan yang diperlukan".

\section{d. Tour dan Travel}

Berdasarkan Surat Keputusan Direktur Jendral Pariwisata No. Kep. 16/U/II/88 tanggal 25 Febuari 1988 tentang ketentuan Usaha Perjalanan, Biro perjalanan adalah kegiatan usaha yang bersifat komersil yang mengatur, menyediakan dan menyelenggarakan pelayanan bagi seseorang, sekelompok orang, unntuk melakukan perjalanan dengan tujuan utama untuk berwisata.

\section{e. Pemesanan}

Menurut Damardjati (2001) medefinisikan bahwa "Booking adalah pemesanan tempat di (restaurant, Travel, theatre, shows, tempat duduk pesawat, kereta api, itercity bus, kamar hotel, dan lain sebagainya)".

\section{METODE PENELITIAN/EKSPERIMEN}

Kerangka penelitian merupakan kerangka hubungan antara konsep-konsep yang ingin diamati atau diukur melalui penelitian yang akan dilakukan. Berdasarkan kerangka penelitian yang ada, maka kerangka penelitian yang digunakan dapat dilihat

\section{Masalah}

Tahapan penelitian dimulai dengan penentuan masalah penelitian yaitu Belum adanya sistem informasi secara online mengenai pemesanan paket Tour

\section{f. Tiket}

Tiket merupakan suatu alat/media yang digunakan oleh perusahaan tertentu sebagai pengganti uang langsung. Tiket biasanya berupa kertas yang didalamnya terdapat item-item tertentu yang menunjukkan suatu nilai.

\section{g. Penyewaan}

Menurut Subekti (2008), penyewaan adalah persetujuan atas manfaat (Barang) dengan penukar (Imbalan). Di dalamnya ada tiga bentuk :

1. Pertama, yaitu persetujuan di dalamnya terjadi pada jasa benda-benda, seperti penyewaan rumah,kendaraan, dan sejenisnya.

2. Kedua, yaitu yang persetujuan didalamnya terjadi pada jasa pekerjaan seperti penyewaan para ahli dalam berbagi bidang untuk melakukan pekerjaan tertentu, jadi yang disewakan adalah jasa yang diperoleh dari pekerjaan, seperti penyewa tukang besi, tukang kayu dan sejenisnya.

3. Ketiga, yaitu persetujuan didalamnya terjadi pada jasa orang lain seperti pembantu, buruh, dan sejenisnya

Travel, penyewaan mobil dan informasi detail mengenai paket Tour.

\section{Pendekatan}

Pendekatan dalam penelitian ini adalah cara peneliti untuk melakukan pendekatan terhadap hal yang akan di teliti diantaranya metode yang digunakan yaitu Extreme Programming . Sedangkan informasi tentang Pemesanan paket Tour dan rental mobil dari pimpinan Smart Tour.

\section{Identifikasi}

55 | STMIK Dian Cipta Cendikia Kotabumi 
Identifikasi dilakukan untuk menganalisis karakter yang akan di teliti Sistem ini menggunakan pernyataan dari pimpinan Smart Tour

\section{Usulan}

Usulan yang digunakan dalam penelitian ini adalah Pemesanan paket Tour dan rental mobil berbasis web menggunakan metode Extreme Programming

\section{Pengujian \\ Pengujian dalam penelitian ini menggunakan pengujian Blackbox.}

\section{Hasil}

Hasil dalam penelitian ini adalah Pemesanan paket Tour dan pemesanan travel mobil dilakukan dengan otomatis dan terjadwal

\section{Tahapan Penelitian}

Tahapan penelitian merupakan kegiatan penelitian yang akan dilakukan secara teremcana, teratur, dan sistematis untuk mencapai tujuan tertentu. Adapun tahapan yang akan dilakukan

\section{Metode Pengumpulan Data}

1. Data Primer

\section{HASIL DAN PEMBAHASAN}

\section{Form Login}

Form login adalah awal ketika akan memasuki menu admin untuk mengelolah data Tour dan Travel yang dapat dilihat pada gambar, maka admin harus menginputkan username dan password yang telah disimpan pada sistem, tampilan form login

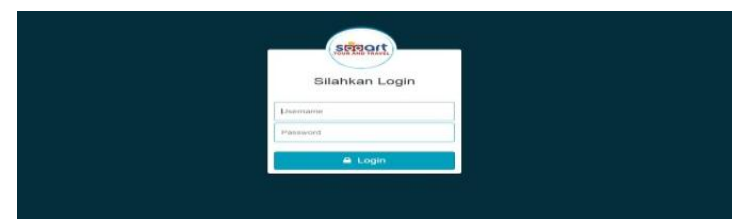

Dalam penelitian ini sumber sumber data penelitian diperoleh secara langsung dari sumber aslinya yang berupa wawancara dengan Pimpinan dari Smart Tour dan pengambilan data pariwisata di Dinas Pariwisata Provinsi Lampung berikut data pariwisata

2. Data Sekunder

Sumber datas sekunder dalam peneltian ini digunakan sebagai data pendukung. Sumber data sekunder diperoleh dari beberapa jurnal penelitian tentang Sistem pelayanan jasa Tour dan Travel pemesanan tiket, Buku-buku dan sumber internet.

\subsection{Rencana Pengujian}

Setelah sistem sudah dibangun, tahap berikutnya adalah melakukan pengujian sistem. Pengujian akan dilakukan menggunakan pengujian Blackbox (Blackbox testing). Blackbox testing adalah suatu metode pengujian perangkat lunak yang berfokus pada sisi fungsionalitas, khususnya pada input dan output aplikasi apakah sudah sesuai dengan apa yang diharapkan atau belum. Pengujian akan dilakukan dengan memberikan sistem pemesanan tiket Travel atau pesawat dan pemesanan rental mobil, kemudian akan dilihat respon sistem dalam memberikan informasi tentang pemesanan tiket Tour dan pemesanan rental mobil berbasis web

dapat dilihat pada gambar 5.1 berikut :

\section{Form Home Admin}

Tampilan home admin adalah awal ketika setelah masuk sebagai admin pada sistem Tour dan Travel. Tampilan home admin dapat dilihat di gambar 5.2 berikut : 


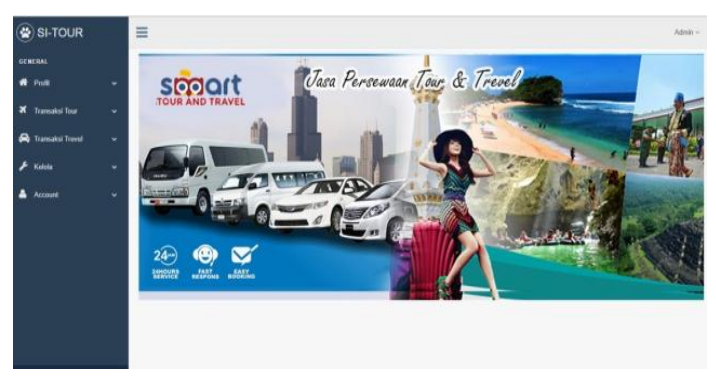

Gambar 5.2 Tampilan Menu Home admin

\section{Form Kelola Travel Mobil}

Tampilan form kelola travel adalah ketika admin akan melakukan proses kelola travel yang dimana admin dapat menambah hapus data Travel. Tampilan kelola Travel dapat dilihat di gambar 5.3 berikut :

Gambar 5.3 Tampilan Kelola Travel Mobil

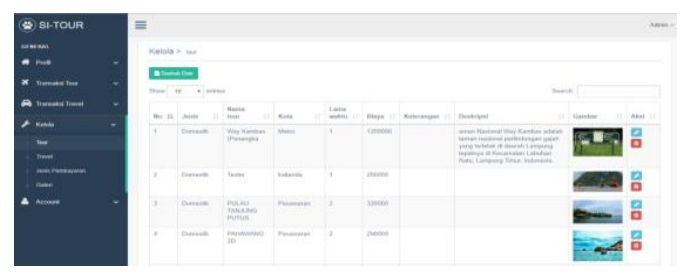

Form Kelola Tour

Tampilan Form kelola Tour adalah proses mengelola Tour dimana admin dapat menambah dan menghapus paket tour yang ada di sistem. Berikut tampilan kelola tour yang dapat dilihat di gambar 5.4 :

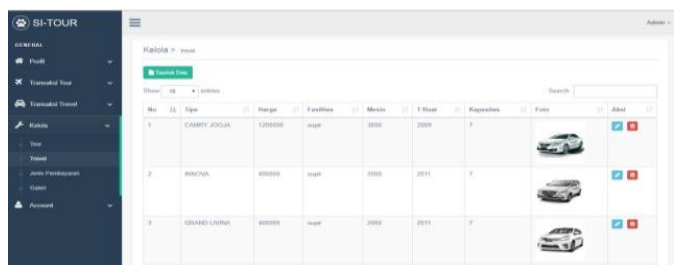

Gambar 5.4 Form Kelola Travel

\section{Form Kelola Jenis Pembayaran}

Tampilan Form kelola jenis pembayaran adalah proses mengelola admin dapat melakukan kegiatan menambah dan menghapus data jenis pembayaran. Berikut tampilan kelola jenis pembayaran yang dapat dilihat pada gambar 5.5 :

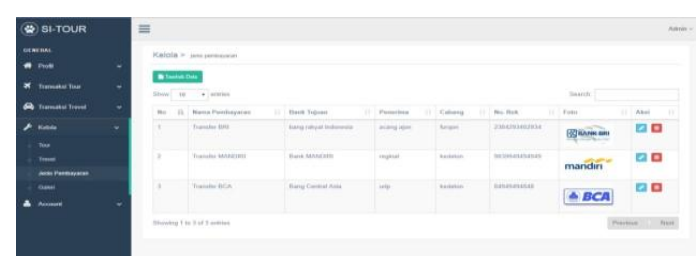

Gambar 5.5 Form Kelola Jenis Pembayaran

\section{Form Paket Wisata Domestik}

Tampilan Form paket wisata domestic adalah tampilan setelah home dimana pelanggan dapat melihat Paket wisata domestic atau dalam negeri. Taapilan paket wisata domestic dapat dilihat pada gambar 5.6 :

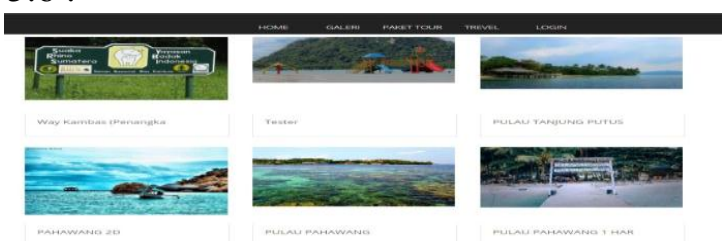

Gambar 5.6 Form Tampilan Paket Wisata

Domestik

\section{Form Paket Wisata Internasional}

Tampilan Form paket wisata internasional adalah tampilan berisi paket wisata internasional atau luar negeri yang dapat dilihat oleh pengguna. Berikut tampilam paket wisata internasional yang dapat dilihat di gambar 5.7 :

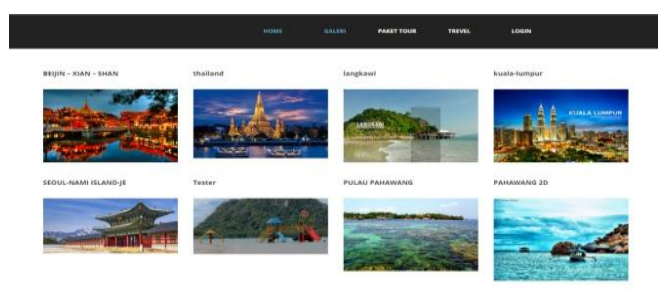


Gambar 5.7 Form Tampilan Paket Wisata

$$
\text { Internasional }
$$

\section{Form Galeri}

Tampilan form galeri adalah tampilan yang dimana terdapat Foto - foto wisata dari berbagai jenis yang dapat dilihat oleh pengguna. Berikut tampilan form galeri dapat dilihat di gambar 5.8.

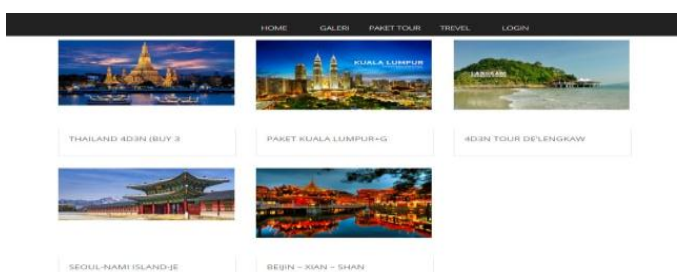

Gambar 5.8 Form Galeri

\section{Menu Home}

Tampilan Home adalah tampilan yang dimana tampilan awal dari website yang dapat dilihat oleh pengguna dan admin smart tour. Berikut tampilan Homedapat dilihat di gambar 5.9.

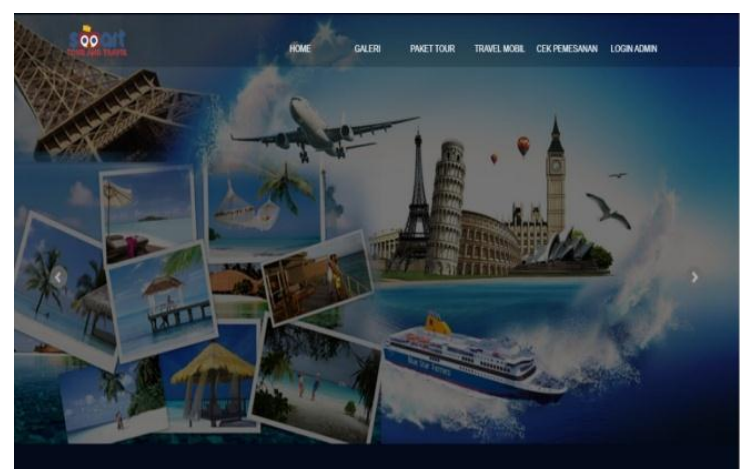

Gambar 5.9 Tampilan Home

\section{Form pemesanan}

Tampilan Form pemesanan adalah tampilan yang data pemesanan Paket tour yang diisi oleh pelanggan pada saat booking. Berikut tampilan data pemesanan dapat dilihat di gambar 5.10

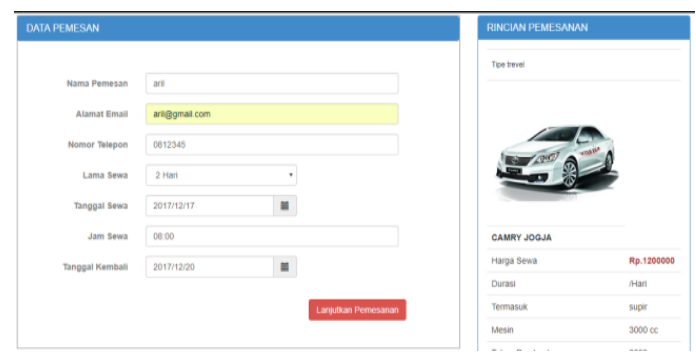

Gambar 5.10 Tampilan menu pemesanan

\section{Form pembayaran}

Tampilan Form pembayaran adalah tampilan yang pembayaran Paket tour yang diisi oleh pelanggan dan terdapat metode pembayaran Transfer maupun Tunai. Berikut tampilan data pembayaran dapat dilihat di gambar 5.11

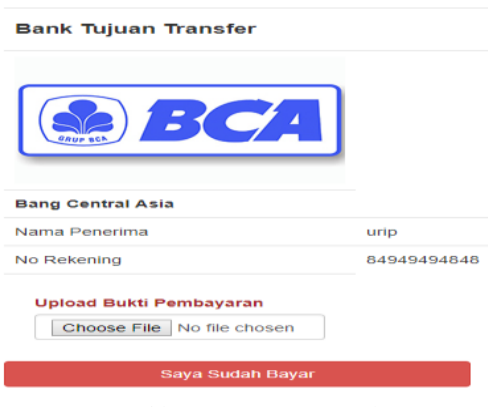

Gambar 5.11 Tampilan MenuPembayaran

\section{Form cek pemesanan Tour}

Tampilan Form cek pemesanan adalah form dimana pelanggan dapat mengecek pemesanan tour yang sudah di pesan sebelumnya. Berikut tampilan form cek pemesanan dapat dilihat di gambar 5.12

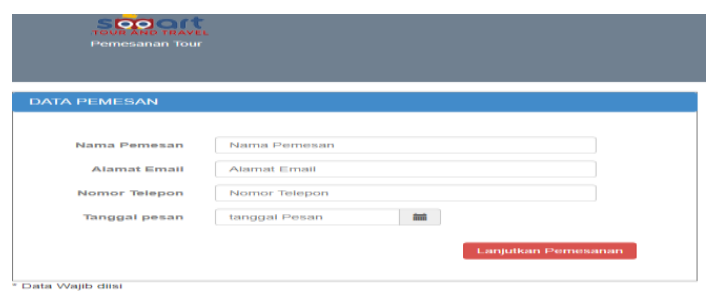

58 | STMIK Dian Cipta Cendikia Kotabumi 
Gambar 5.12 Form tampilan Cek pemesanan tour

\section{Form Upload bukti pembayarann}

Tampilan Form upload bukti pembayaran adalah mengupload bukti pembayaran melalui transfer dan jika pelanggan langsung bayar di tempat dapat menekan tomboll Saya sudah bayar. Berikut tampilan form upload bukti pembayaran dapat dilihat di gambar 5.13

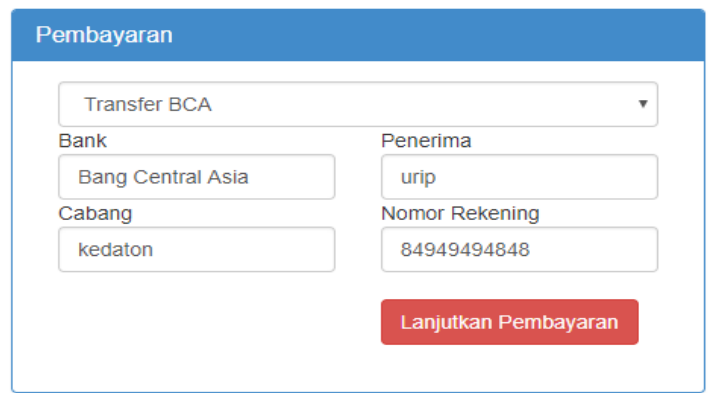

Gambar 5.13 Form tampilan upload bukti pembayaran

\section{Form data pemesanan travel mobil}

Tampilan Form upload bukti
pembayaran adalah tampilan form
pemesanan travel mobil yang dapat diisi oleh
pelanggan. Berikut tampilan form data
pemesanan travel mobil dapat dilihat di
gambar 5.14

Gambar 5.14 Form pemesanan data travel

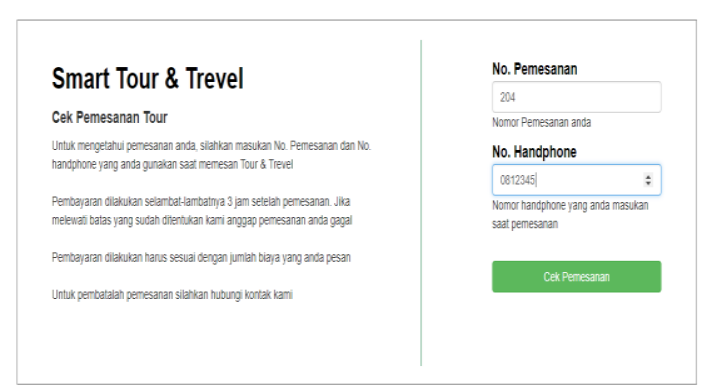

\section{KESIMPULAN}

Berdasarkan hasil dari penelitian maka di dapatkan beberapa simpulan sebagai berikut :

1. Sistem informasi pelayanan jasa tour dan travel berbasis web (Studi kasus Smart Tour) dapat mempermudah pelanggan dan mengelola data secara cepat, selain itu menyediakan jasa travel mobil agar pelanggan dapat langsung memesan travel mobil yang diinginkan tanpa harus datang langsung kekantor Smart tour.

2. Sistem informasi pelayanan jasa tour dan travel berbasis web (Studi kasus Smart Tour) mampu mengurangi resiko kesalahan pada pengelolaan data pada admin

3. Sistem informasi pelayanan jasa tour dan travel berbasis web (Studi kasus Smart Tour) telah mampu mengurangi waktu yang terbuang pada saat pelanggan memesan tiket tour dengan menghasilkan kriteria baik yaitu persentase tanggapan responden sebesar $100 \%$.

\section{PUSTAKA}

[1] Basuki, Awan. 2010. Membangun Web Berbasis PHP dengan Framework Codeigniter. Lokommedia:

Yogyakarta.

[2] Budi Raharjo, dkk, .(2010). Modul Pemograman Web (PHP, HTML, MYSQL). Bandung: Modula.

[3] Basu Swastha, 2000. Pemesanan bidang usaha. Yogyakarta : Penerbit BPFI. 
[4] Cheyne, J., Downes, M., and Leeg, S., 2006. Travel Agents vs Internet: What Influences Travel Customer Choises?, Journal of Vaction Marketing, 12 (1), 41-57.

[5] Damardjati, R.S 1989, Istilah-istilah Dunia Pariwisata,Jakarta: Pradnya Paramitha

[6] Desy Iba Ricoida.(2017). Perancangan sistem informasi rumah travel dan tour. Jurnal TAM (Teknology Acceptence Mode) , 8, 8-12

[7] Dwi Mustika Kusumawardi \& sediyono, e. (2016). Sistem manakemen rantai pasok pariwisata untuk produk wisata pada agen tour dan travel dengan analynis swot dan metode analytic network process. Jurnal sistem informasi bisnis , 08, 1-9.

[8] Dinas Pariwisata Provinsi Lampung, Pariwisata Dalam Angka Tahun 2016, 2016

[9] Febriyanto, N. (2009). Sistem informasi tour dan travel perjalanan ibadah haji dan umrah berbasis website pada Pt.Zulian kamasaindo palembang. Seminar nasional teknoklogi informasi dan multimedia STIMIK AMIKOM yogyakarta , 2-6.

[10] Giang G Maulana (2015). Sistem informasi pelayanan jasa tour dan travel berbasis website elektronik (studi kasus nietours). Jurnal online institut teknologi nasional , 03, 1-12.

[11] Isnandi, I. u. (2014). Sistem informasi penjualan tiket pada al fath tours dan travel Pacitan. Journal speedsentra penelitian engineering dan edukasi , 6, 1-5.

[12] Jogiyanto, HM. (1995). AnalisisdanDesainSistemInformas i(PendekatanTerstruktur).

Yogyakarta: Andi Offset.

[13] Kendall dan kendall.2011. Analisis dan Perancangan Sistem,versi Bahasa Indonesia, edisi ke 5 jilid ke 1.Jakarta :PT.INDEKSKendall, E. Kenneth; \& Kendall, E. Julie., 2011, Systems Analysis and Design. Eighth Edition. United States of America : Pearson Education Inc

60 | STMIK Dian Cipta Cendikia Kotabumi 
[14] Lena, Sonty, s Kom, and f mochamad ridwan. "perangkat lunak pemesanan paket wisata berbasis web d'dara tour dan travel bandung." Teknik informatika, 2013: $1-6$

[15] Nugroho, Adi. Analisis dan Perancangan Sistem Informasi. Penerbit informatika, Bandung : BIOBSES,2005

[16] Nugroho, Bunafit. 2008. Trik dan Rahasia Membuat Aplikasi Web Dengan PHP. Yogyakarta : Gaya Media.

[17] Munawar. (2005), Pemodelan Visual dengan UML, Graha Ilmu, Yogyakarta, 17-100.

[18] Octafiani, D. t. (2015). Web Multi ecommerce berbasis framework codeigniter. Teknologi dan informatika (Teknomatika) , 1..

[19] Pressman, R. S. (2010). Software engineering: a practitioner's approach $7^{\text {th }}$ edition. New York: McGraw-Hill
[20] Raharjo, B., I. H., \& E. R. 2010. Modul Pemograman WEB(HTML, PHP \& MYSQL.

[21] Subekti dan R. Tjiro Sudibyo. 1995. KUH Perdata. Jakarta; PT. Pradnya Paramitra

[22] Siena.2010. Cara Mudah Memadukan Web Design dan Web Programming. Jakarta : Elexmedia Komputindo

[23] sutabri, tata,2012,konsep sistem informasi.yogyakarta:andi.

[24] Sutarman. 2012. Buku Pengantar Teknologi Informasi. Jakarta: Bumi Aksara.

[25] Siena, I. (2009, agustus 04). Retrieved oktober 2, 2011, from http://my.opera.com/aviciena/blog /2009/08/14 /framework-3

[26] subaidi, A. (2015). Sistem informasi biro perjalanan tour berbasis website dengan menggunakan framework codeigniter pada anggoda indonesia tour dan travel. Jurnal of information and Technology, 03, 1-13.

61 | STMIK Dian Cipta Cendikia Kotabumi 
[27] Undang-Undang Republik Indonesia

Nomor 10 tahun 2009.

Kepariwisataan.

[28] Wetherbe, James.2012.buku Systems

Analysis and Design :

Traditional, Best Practices 4th

Ed 